\title{
Hipertansiyon sıklığı, farkındalığı, tedavi alma ve kan basıncı kontrolünü etkileyen etmenler
}

\author{
Determinants of prevalence, awareness, treatment and control of high blood pressure
}

\author{
Kaan Sözmen', Gül Ergör ${ }^{2}$, Belgin Ünal ${ }^{2}$
}

\section{ÖZET}

Amaç: Bu çalışmada İzmir ili Balçova İlçesi'nde yaşayan 30 yaş ve üzeri bireylerde hipertansiyon $(H T)$ sıklığı ve HT farkındalık, tedavi ve kontrol düzeylerini etkileyen etmenlerin değerlendirilmesi amaçlanmıştır.

Yöntemler: Balçova'nın Kalbi Projesi kapsamında 20072009 yılları arasında durum saptama aşamasına katılan 12,742 kişinin verisi değerlendirilmiştir. Ortalama kan basıncı $\geq 140 / 90 \mathrm{mmHg}$ üzerinde olan ya da antihipertansif ilaç kullanan bireyler "hipertansiyonu var" olarak kabul edilmişlerdir. HT varlığı, farkındalık, tedavi ve kontrol düzeylerini etkileyen etmenler çok değişkenli lojistik regresyon analizi ile değerlendirilmiştir.

Bulgular: Hipertansiyon sıklığı erkeklerde \%39,5, kadınlarda $\% 41,6$ ve toplamda $\% 40,9$ olarak bulunmuştur. Hipertansif olan bireylerin \% 73,3'ü sağlık durumlarının farkındadır. HT varlığının farkında olan bireylerin ise \%90,9'u ilaç tedavisi almakta ve \%49,6'sının kan basıncı kontrol altında bulunmaktadır. Artan yaş, kadın cinsiyet, sağlık algısının kötü olması, fiziksel inaktivite, bel çevresinin sınır değerin üstünde olması koroner kalp hastalığı $(\mathrm{KKH})$, Diyabet (DM) veya hiperlipidemi tanısı ve ailede KKH öyküsü HT görülme olasılığını artırmıştır. HT farkındalığını ise artan yaş, erkek cinsiyet, $\mathrm{KKH}$, inme, DM, hiperlipidemi varlığı ve ailede KKH öyküsü olması olumlu etkiler iken tadına bakmadan tuz kullanan bireylerde farkındalık düzeyi anlamlı olarak düşük bulunmuştur. HT kontrolü artan yaş ile birlikte azalırken, erkeklerde daha yüksek bulunmuştur.

Sonuç: Bu çalışmada HT farkındalık, tedavi ve kontrol oranları diğer çalışmalara göre daha yüksektir. Kadın cinsiyet, kronik hastalık ve ailede KKH hikayesi varlığı farkındalık ve kontrolü artırırken erkek cinsiyet ve obezite varlığı kontrol düzeylerini olumsuz etkilemektedir. Farkındalığın yüksek olmasına rağmen kontrol oranlarının düşük olmasının nedenleri ileri çalışmalarla incelenmesi gerekmektedir.

Anahtar kelimeler: hipertansiyon, prevalans, farkındalık, tedavi, kontrol

\begin{abstract}
Objective: The aim of the study was to evaluate prevalence, awareness, treatment and control rates of hypertension (HT) and associated factors among individuals over 30 years old living in Balcova District of Izmir.
\end{abstract}

Methods: Data from 12,742 individuals who participated the baseline study of Heart of Balcova Project during 2007-2009 was evaluated. HT was defined as mean blood pressure $\geq 140 / 90 \mathrm{mmHg}$ or being on antihypertensive medication. Multivariate logistic regression analysis was applied to assess the determinants of prevalence, awareness, treatment and control of high blood pressure.

Results: The overall prevalence of HT was $39,5 \%$ in male, $41.6 \%$ in female and $40,9 \%$ in total. Among participants with $\mathrm{HT}, 73.3 \%$ were aware of it. Among participants aware of $\mathrm{HT} 90.9 \%$ were treated, $49.6 \%$ of those treated were controlled (BP $<140 / 90 \mathrm{mmHg}$ ). HT presence was associated with increasing age, female gender, poor self assessed health, physical inactivity, high waist circumference, diagnosis of coronary heart disease(CHD), diabetes or hyperlipidemia, family history of CHD. Awareness of $\mathrm{HT}$ was positively associated with increasing age, male gender, CHD, stroke, DM, hyperlipidemia, and history of CHD. Awareness was lower among individuals who added salt without tasting the meal. HT control was significantly higher among men while it decreased with increasing age.

Conclusion: In this study awareness, treatment and control rates for HT were higher compared to other studies. While female gender, presence of chronic diseases and family history of CHD increased awareness and control, male gender and obesity had negative impact on control rates. The reasons behind low control rates despite high awareness should be explored in further studies.

Key words: Hypertension, prevalence, awareness, treatment, control

${ }^{1}$ Kâtip Çelebi Üniversitesi, Tıp Fakültesi, Halk Sağlı̆̆ı Anabilim Dalı, İzmir, Türkiye

${ }^{2}$ Dokuz Eylül Üniversitesi, Tip Fakültesi, Halk Sağlı̆̆ı Anabilim Dalı, İzmir, Türkiye

Yazışma Adresi /Correspondence: Kaan Sözmen, Izmir Kâtip Çelebi Üniversitesi, Tıp Fakültesi, Halk Sağlığı Anabilim Dalı İmir, Türkiye Email: drmelihkaan@hotmail.com

Geliş Tarihi / Received: 03.04.2015, Kabul Tarihi / Accepted: 26.05.2015

Copyright @ Dicle Tıp Dergisi 2015, Her hakkı saklıdır / All rights reserved 


\section{GíRIŞ}

Yüksek kan basınc1, kardiyovasküler mortalitenin önde gelen nedenlerinden biri olup dünyada her yıl 7.5 milyon kişinin ölümüne neden olmaktadır ve bu küresel ölümlerin \%12,8'ini oluşturmaktadır. Dünya Sağlık Örgütü verilerine göre yüksek kan basınc1 57 milyon yeti yitimine ayarlanmış yaşam yılı (DALY) kaybına yol açmaktadır [1]. Yapılan projeksiyonlara göre 2030 yılında 23 milyon kardiyovasküler ölümün hipertansiyon (HT) ile ilişkili olacağ1 ve bu ölümlerin \%85'inin düşük ve orta gelirli ülkelerde gerçekleşeceği bildirilmiştir [2]. Son 3 dekatta epidemiyolojik dönüşüm sonucunda bulaşıcı hastalıklardan bulaşıcı olmayan hastalıklara geçişin yaşandığ 1 bir çok gelişmekte olan ülkede HTönemli bir halk sağlığı sorunu olarak kabul edilmektedir. Yakın zamanda 136 ülkenin verisi kullanılarak yapılan bir çalışmaya göre son 30 yıllık sürede kan basincı kontrol altında olmayan birey sayısının 3 milyar kişiye ulaştığ bildirilmiştir [3]. Bunun yanında HT'un yaratmış olduğu küresel ekonomik yük yaklaşık 370 milyar dolar olarak hesaplanmış olup bu tüm sağlık harcamalarının \%10'unu oluşturmaktadır [4].

Hipertansiyonun farkına varılmaması ya da etkili tedavi edilmemesi nedeniyle bireyler önlenebilir ancak ölümcül olabilen koroner kalp hastalığı, iskemik ve hemorajik inmenin yanında kalp yetmezliği, periferik damar hastalığı, böbrek yetmezliği ve görme bozuklukları açısından artmış riske sahiptirler. HT'nin erken tanıs1 ve tedavisinin sistolik kan basınc1 $140 \mathrm{mmHg}$, diyastolik kan basıncinı 90 mmHg'nin altında olacak biçimde düzenlemek ve gerekli yaşam biçim değişikliklerini yapmak kardiyovasküler komplikasyonların ve ölümlerin önlenmesi açısından önemlidir. Ancak yapılan çalışmalarda HT tanı, tedavi ve kontrol oranlarının geleneksel olarak yarımlar kuralını izlediği bildirilmiştir; bireylerin yarıs1 HT tanıs1 almakta, tan1 konan HT hastalarının yarısı tedavi almakta ve tedavi alan hipertansif bireylerin ise yarısının kan basincı düzeyleri kontrol altında bulunmaktadır [5]. Gelişmiş ülkelerde yapılan çalışmalarda tanı ve tedavi oranlarında artış olduğu bildirilmiştir. Ancak gelişmekte olan ülkelerde HT farkındalık ve kontrol oranlarının daha düşük olduğu gösterilmiştir [6]. Ülkemizde daha önce yapılan çalışmalarda HT sıklığının \%25-
$\% 32$ arasında, HT kontrolünün ise $\% 16,4-\% 28,7$ arasında değiştiği bildirilmiştir [7-9].

Bu çalışmada Balçova'da yaşayan 30 yaş ve üzeri bireylerde HT sıklığ 1 ve HT farkındalık, tedavi ve kontrol düzeylerini etkileyen etmenlerin değerlendirilmesi amaçlanmıştır.

\section{YÖNTEMLER}

$\mathrm{Bu}$ araştırma kesitsel tipte olup, İzmir'de yürütülen Balçova'nın Kalbi Projesi (BAK) kapsamında 2007-2009 yılları arasında durum saptama aşamasına katılan 12,742 kişinin verisi değerlendirilmiştir. BAK Projesi, Balçova'da oturan 30 yaş üstü bireylerde Kalp-Damar hastalıklarının (KDH) gelişimini önlemek amaciyla Balçova Belediyesi ve Dokuz Eylül Üniversitesi Tıp Fakültesi (DEÜTF) arasında imzalanan protokol ile başlatılmıştır. Proje kapsaminda örnek seçilmemiş olup Balçova'da oturan tüm bireylere ulaşılması hedeflenmiştir. Projeye katılmayı kabul eden bireylere sosyodemografik özellikler ve yaşam alışkanlıkları ile ilişkili özelliklerin sorgulandığı anketler eğitimli anketörler tarafından bireylerin evleri ziyaret edilerek uygulanmıştır. Sonrasinda bireyler semt evlerine ileri inceleme için davet edilmiştir. Semt evlerine gelen bireylerin tıbbi öyküleri halk sağlığ tarafından sorgulanmıştır. Kan basıncı, en az beş dakikalık dinlenmeden sonra sağ koldan sfingomanometre ile iki kez aynı hemşire ya da araştırma görevlisi tarafından ölçülmüştür. Diyastolik ve sistolik kan basınçları, bu iki ölçümün ortalaması alınarak belirlenmiştir [10]. Antropometrik ölçümler (boy, bel çevresi ve ağırlık) eğitimli kişiler tarafından standard ölçüm yöntemleri ile yapılmıştır. En az 8 saatlik açlık sonrası alınan kan örneklerinden kolesterol, trigliserid ve kan şekeri analizleri DEÜTF Hastanesi Biyokimya laboratuvarı tarafindan yapı1miştır.

$\mathrm{Bu}$ araştırmanın bağımlı değişkenleri hipertansiyon (HT) varlığı, farkındalık, tedavi ve kan basıncının kontrol altında olma durumudur. Daha önce HT tanısı almamış kişilerde ortalama kan basıncının $\geq 140 / 90 \mathrm{mmHg}$ üzerinde olması durumunda ya da daha önce doktor tarafindan HT tanısı alan ve antihipertansif ilaç kullanan bireyler "HT var" olarak kabul edilmişlerdir. HT'da farkındalık, ölçümle yüksek tansiyon saptanan kişiler arasında doktor tanısına dayalı HT bildirenler olarak tanımlanmıştır. 
Yüksek kan basıncı nedeniyle ilaç kullanan bireylerin Sistolik Kan Basinc $<140 \mathrm{mmHg}$ ve Diyastolik Kan Basınc1<90 mmHg olması durumunda HT'nin kontrolde olduğu kabul edilmiştir [10].

Bağımsız değişkenler: Sosyodemografik özelliklerden yaş sürekli değişken olarak alınırken, cinsiyet(erkek/kadın), medeni durum(evli/bekar, boşanmış, dul), eğitim düzeyi ("okur-yazar değil”, "okuryazar", "ilkokul”, “ortaokul”, "lise” ve "üniversite"), sağlık güvencesi varlığı(sosyal güvence yok, emekli sandığ1, Bağ-Kur, özel sigorta, SSK), olarak gruplandırılmıştır. Yaşam biçim davranışlar1 ile ilgili olarak; yemeklerin tadına bakmadan tuz atma (evet/hayır), haftada 5 gün en az 30 dakika orta düzeyde fiziksel aktivite yapma (evet/hayır), hayatının herhangi bir döneminde düzenli sigara kullanma durumu (evet/hayır) olarak değerlendirilmiştir. Sağlık algısı "sağl1k durumunuzu nasıl değerlendirirsiniz?' sorusu verilen seçeneklere göre çok iyi, iyi yanıtını verenler 'iyi'; orta, kötü, çok kötü yanıtını verenler ise "kötü" sağlık algısı var olarak sınıflanmiştır [11,12].

Obezite varlığ 1 bel çevresinin erkeklerde $>102 \mathrm{~cm}$, kadinlarda $>88 \mathrm{~cm}$ olmas 1 olarak tanımlanmıştır [13]. 12 saatlik açlık sonrası alınan kanda açlık kan şekeri (AKŞ) düzeyi $126 \mathrm{mg} / \mathrm{dl}$ ve üzerinde ise ya da daha önceden diyabet tanısı almışsa bireylerde DM var olarak kabul edilmiştir (22). Hiperlipidemi tanısı alan ve kolesterol düşürücü ilaç kullanan bireyler ile LDL-Kolesterol düzeyi 130 $\mathrm{mg} / \mathrm{dl}$ ve üzerinde olanlarda hiperlipidemi olduğu kabul edilmiştir [14].

Ailede kalp hastalığg öyküsü; baba ya da erkek kardeşte 55 yaş ve öncesinde, anne ya da kız kardeşte 65 yaşından önce Koroner Kalp Hastalığ (KKH) olması durumu olarak tanımlanmıştır [15]. Daha önce Koroner Kalp Hastalığı varlığı, inme, diyabet varlı $\breve{g} 1$, hiperlipidemi tanıs1 alma durumları Halk Sağlığı araştırma görevlileri tarafından kontrol edilmiştir. Çalışmanın etik kurul onayı DEÜTF Klinik Araştırmalar Değerlendirme Komisyonu tarafından alınmıştır. Araştırmaya katılan bireylere gönüllü bilgilendirme formu okunmuş, imzalı onayları alınmıştır. Projenin uygulanması ile ilgili ayrıntılara yöntem makalesinden ulaşılabilmektedir [16].

Araştırma verilerinin istatistiksel değerlendirmesinde SPSS 15.0 istatistik paket programı kul- lanıldı. Ölçümsel değişkenler ortalama \pm standart sapma (SD) ile, kategorik değişkenler sayı ve yüzde (\%) ile sunuldu. Veri çözümlemede, ki-kare testi ve çok değişkenli lojistik regresyon analizinden yararlanılmıştır. Çok değişkenli lojistik regresyon analizinde tüm bağımsız değişkenler modele alınmıştır. Regresyon analizinde medeni durum değişkeni için tek değişkenli analizlerde HT kontrol yüzdesi en yüksek olan "boşanmış" grup referans kategori olarak kabul edilmiştir. Regresyon modellerinden elde edilen olasılıklar oranları (OR) \%95 güven aralıkları ile birlikte sunulmuştur. Anlamlılık düzeyi olarak $\mathrm{p}<0,05$ alınmıştır.

\section{BULGULAR}

Bu çalışmada 12,742 kişinin verisi değerlendirilmiş olup, bireylerin \% 33,4'ü ( $\mathrm{n}=4255)$ erkek, \% 66.6's1 $(\mathrm{n}=8487)$ kadındır. Katılımcıların cinsiyete göre sosyodemografik ve klinik özellikleri Tablo 1'de gösterilmiştir. Erkeklerin yaş ortalaması $53,9 \pm 12,9$, kadınların 51,8 $\pm 12,9$ olup aradaki fark istatistiksel olarak anlamlıdır $(\mathrm{p}<0,05)$. Erkeklerin eğitim düzeyi kadınlara göre anlamlı olarak yüksektir. Kadınlarda ilkokul ve alt1 eğitim düzeyine (okur yazar-okur yazar değil) sahip birey oranı \%13,6 iken, erkeklerde bu oran \%3,0 olarak bulunmuştur. Kötü sağlık alg1s1, yüksek bel çevresi, hiperlipidemi ve HT varlı̆̆ kadınlarda, KKH varlığı, DM varlığı, sigara kullanımı, tadına bakmadan tuz kullanma ise erkeklerde anlamlı olarak daha sık görülmüştür.

HT sıklı̆̆ 1 , farkındalık, tedavi ve kontrolüne ait oranların değişkenlere göre dağılımı Tablo 2'de gösterilmiştir. Bu çalışmada HT sıklığ 1 erkeklerde $\% 39,5$, kadinlarda $\% 41,6$ ve toplamda $\% 40,9$ olarak bulunmuştur. HT sıklığı yaşla birlikte artmakta olup 30-39 yaş grubunda \% 11,0 olan HT sıklı̆̆ 1,70 yaş ve üstü grupta \% 84,9'a ulaşmaktadır (eğimde ki-kare için $\mathrm{p}<0,05)$. HT olan bireylerin \% 73,3'ü daha önce doktor tarafindan HT tanısı konduğunu ve bu durumun farkında olduğunu bildirmiştir. HT varlığının farkında olan bireylerin ise \%90,9'u kan basıncı düşürücü ilaç tedavisi almaktadır. İlaç tedavisi alan bireylerin \%49,6'sının kan basıncı düzeyi, kan basıncı için kontrol düzeyi olarak kabul edilen 140/90 mmHg'nin altındadır. Diğer bir ifade ile daha önceden HT tanısı olan ve yeni tanı konulan tüm hipertansif bireyler değerlendirildiğinde, hipertansiflerin \%66,7'si tedavi almakta ve bu bireylerin 
\%33'ünün kan basıncı kontrol altında bulunmaktadır. Kadınlarda HT görülme sıklığı, farkındalık ve tedavi oranları erkeklere göre daha yüksek iken, HT kontrol oranları açısından cinsiyetler arasında anlamlı fark bulunmamıştır.

HT varlığı, farkındalık, tedavi ve kontrolü ile bağımsız değişkenlerin ilişkisi çok değişkenli lojistik regresyon analizi ile değerlendirilmiştir ve düzeltilmiş olasılıklar oranları Tablo 3'de sunulmuştur. HT varlığ 1 artan yaş ile birlikte anlamlı olarak artış göstermiştir. 30-39 yaş grubu referans olarak alındığında, 50-59 yaş grubunda HT varlığ 1 için OR: 6,28(\%95GA:5,44-7,26), 70 yaş ve üstü grupta ise HT varlığı için OR: 21,38 (\%95GA:16,4427,80) olarak bulunmuştur. Erkekler, kadınlara göre HT varlığ1 açısından daha düşük riske sahiptirler OR:0,83 (\%95GA:0,74-0,93). Sağlık alg1s1 kötü olanlarda, yeterli düzeyde fizik aktivite yapmayanlarda, bel çevresi sınır değerin üstünde olan bireyler HT'ye sahip olma açısından artmış riske sahip olduğu bulunmuştur. Hastalık sorgulamasında $\mathrm{KKH}$, DM ve hiperlipidemi olması HT riskini sirasıyla, $1,72,2,78$ ve 1,30 kat artırmaktadır. Ailede KKH öyküsü olan bireyler için HT görülme riski 3,84 kat artmaktadır. Sigara kullanmış ya da şu anda sigara kullanan bireylerde ve yemeklerin tadına bakmadan tuz kullanan bireylerde HT için azalmış risk bulunmuştur. Medeni durum, sosyal güvence varlığı ile HT varlığ 1 arasında anlamı bir ilişki bulunmamıştır.

Çok değişkenli lojistik regresyon analizine göre HT için farkındalık sıklığı artan yaş ile artış göstermiştir. Erkeklerde farkındalık düzeyi kadınlara göre anlamlı olarak daha düşük bulunmuştur. HT farkındalığı için OR değerleri; KKH olanlarda 4,35 (\%95 GA:3,15-6,03), inme öyküsü olanlarda 2,03 (\%95GA:1,20-3,42), DM tanis1 olanlarda 1,95(\%95GA:1,57-2,41), hiperlipidemiklerde 1,46(\%95 GA:1.25-1.72) ve ailesinde KKH öyküsü olanlarda 12,72(\%95 GA:10,72-15,08) olarak bulunmuştur. Tadına bakmadan tuz kullanan bireylerde ise farkındalık anlamlı olarak düşük bulunmuştur, OR: 0,52(\%95 GA:0,42-0,65). Sosyal güvence varlığ 1 , fiziksel aktivite, bel çevresi ile HT farkındalığı arasında anlamlı bir ilişki bulunmamıştır.

Çok değişkenli lojistik regresyon analizine göre tedavi alma durumu artan yaş ile birlikte artış göstermekte iken, medeni durum, eğitim seviyesi tedavi almayı anlamlı olarak etkilememiştir. Er- keklerde tedavi alma düzeyi kadınlara göre anlamlı olarak düşük bulunmuştur, OR: 0,73(\%95GA:0,540,98). Sağlık algıs1, fiziksel aktivite durumu, sigara kullanım durumu ile HT tedavisi arasında anlamlı ilişki bulunmamıştır. HT varlığının farkında olmasına rağmen yemeklerde tadına bakmadan tuz kullanan bireylerde ise kan basıncı düşürücü tedavi alma oranları tuz kullanmayan bireylere göre anlamlı olarak düşük bulunmuştur; OR:0,70(\%95GA:0,50-0,99). KKH, DM ve hiperlipidemi tan1s1 olan bireylerde kan basıncı düşürücü tedavi alma için olasılıklar oranları bu hastalık tanıları olmayan bireylere göre sirasiyla 1,82, 1,63 ve 1,29'dur. Ancak inme tanısı almış olma tedavi alma durumunu anlamlı olarak etkilememiştir.

Tablo 1. Değişkenlerin cinsiyete göre dağılımı

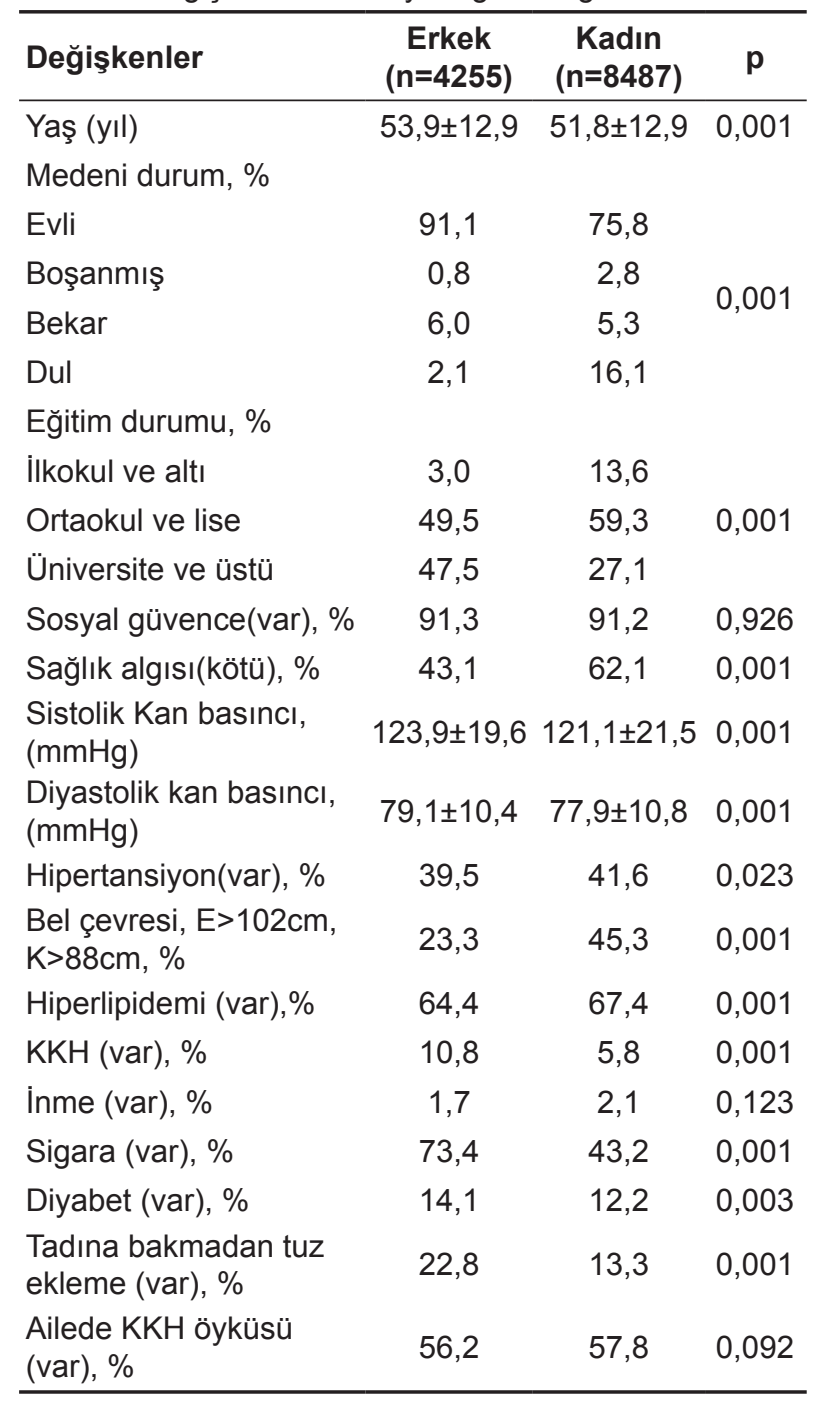

KKH: Koroner Kalp Hastalığı 
Tablo 2. Hipertansiyon varlığı, farkındalık, tedavi ve kontrol oranları

\begin{tabular}{|c|c|c|c|c|c|c|c|c|}
\hline Değişkenler & HT varlığı & $\mathbf{p}$ & Farkındalık & $\mathbf{p}$ & Tedavi & $\mathbf{p}$ & HT Kontrolü & $\mathbf{p}$ \\
\hline \multicolumn{9}{|l|}{ Yaş (yıl) } \\
\hline 30-39 & 11,0 & 0,001 & 46,9 & 0,001 & 73,0 & 0,001 & 87,2 & 0,001 \\
\hline $40-49$ & 34,0 & & 68,2 & & 85,8 & & 74,5 & \\
\hline $50-59$ & 57,6 & & 75,9 & & 91,9 & & 66,1 & \\
\hline $60-69$ & 75,1 & & 79,3 & & 94,2 & & 58,6 & \\
\hline 70 ve üstü & 84,6 & & 81,2 & & 96,6 & & 51,5 & \\
\hline \multicolumn{9}{|l|}{ Cinsiyet } \\
\hline Kadın & 41,6 & 0,028 & 78,7 & 0,001 & 91,6 & 0,013 & 49,6 & 0,962 \\
\hline Erkek & 39,5 & & 61,9 & & 89,0 & & 49,7 & \\
\hline \multicolumn{9}{|l|}{ Medeni durum } \\
\hline Evli & 37,6 & 0,001 & 71,5 & 0,001 & 89,6 & 0,001 & 53,3 & 0,001 \\
\hline Boşanmış & 33,9 & & 65,6 & & 86,9 & & 64,2 & \\
\hline Bekar & 23,4 & & 66,0 & & 91,6 & & 44,9 & \\
\hline Dul & 71,8 & & 84,4 & & 95,2 & & 38,8 & \\
\hline \multicolumn{9}{|l|}{ Eğitim durumu } \\
\hline İlkokul ve altı & 67,9 & 0,001 & 83,0 & 0,001 & 92,1 & 0,017 & 41,4 & 0,001 \\
\hline Ortaokul ve lise & 43,7 & & 74,1 & & 91,5 & & 50,3 & \\
\hline Üniversite ve üstü & 27,4 & & 67,9 & & 88,5 & & 55,6 & \\
\hline \multicolumn{9}{|l|}{ Sosyal güvence } \\
\hline Var & 42,0 & 0,001 & 74,3 & 0,001 & 91,4 & 0,001 & 49,9 & 0,225 \\
\hline Yok & 27,7 & & 55,1 & & 79,6 & & 43,8 & \\
\hline \multicolumn{9}{|l|}{ Sağlık algısı } \\
\hline İyi & 34,0 & 0,001 & 65,2 & 0,001 & 91,0 & 0,890 & 52,0 & 0,060 \\
\hline Kötü & 46,5 & & 78,1 & & 90,8 & & 48,5 & \\
\hline \multicolumn{9}{|c|}{ Tada bakmadan tuz kullanma } \\
\hline Evet & 31,0 & 0,001 & 61,5 & 0,001 & 87,6 & 0,013 & 49,9 & 0,918 \\
\hline Hayır & 42,6 & & 75,6 & & 91,3 & & 49,6 & \\
\hline \multicolumn{9}{|l|}{ Fizik aktivite } \\
\hline Var & 37,9 & 0,001 & 71,7 & 0,007 & 90,2 & 0,146 & 52,2 & 0,004 \\
\hline Yok & 44,7 & & 74,9 & & 91,6 & & 47,2 & \\
\hline \multicolumn{9}{|l|}{ Sigara } \\
\hline Hiç kullanmamış & 47,5 & 0,001 & 75,2 & 0,020 & 92,1 & 0,006 & 45,5 & 0,001 \\
\hline Kullanmış & 34,7 & & 72,3 & & 89,5 & & 55,0 & \\
\hline \multicolumn{9}{|l|}{ KKH varlığı } \\
\hline Evet & 74,5 & 0,001 & 91,7 & 0,001 & 95,6 & 0,001 & 48,3 & 0,487 \\
\hline Hayır & 37,9 & & 71,5 & & 90,0 & & 50,0 & \\
\hline \multicolumn{9}{|l|}{ İnme Varlığı } \\
\hline Evet & 81,1 & 0,001 & 88,4 & 0,001 & 90,3 & 0,763 & 39,2 & 0,009 \\
\hline Hayır & 39,8 & & 73,6 & & 90,9 & & 50,1 & \\
\hline \multicolumn{9}{|l|}{ Bel çevresi } \\
\hline Yüksek & 61,1 & 0,001 & 77,5 & 0,001 & 93,2 & 0,001 & 44,1 & 0,001 \\
\hline Normal & 28,5 & & 67,6 & & 87,5 & & 58,5 & \\
\hline \multicolumn{9}{|l|}{ Diyabet } \\
\hline Var & 73,4 & 0,001 & 85,3 & 0,001 & 94,5 & 0,001 & 44,6 & 0,001 \\
\hline Yok & 36,0 & & 69,6 & & 89,5 & & 51,6 & \\
\hline \multicolumn{9}{|l|}{ Hiperlipidemi } \\
\hline Var & 46,4 & 0,001 & 75,0 & 0,001 & 91,9 & 0,001 & 49,6 & 0,166 \\
\hline Yok & 29,8 & & 69,7 & & 87,7 & & 49,7 & \\
\hline \multicolumn{9}{|l|}{ Ailede KKH öyküsü } \\
\hline Var & 54,0 & 0,001 & 86,0 & 0,001 & 90,7 & 0,303 & 48,4 & 0,001 \\
\hline Yok & 22,0 & & 35,1 & & 92,3 & & 54,2 & \\
\hline
\end{tabular}


Tablo 3. Çok değişkenli regresyon analizine göre hipertansiyon varlığı, farkındalık, tedavi ve kontrolünü etkileyen etmenler

\begin{tabular}{|c|c|c|c|c|}
\hline & $\begin{array}{l}\text { HT varlığı } \\
(n=12742)\end{array}$ & $\begin{array}{l}\text { Farkındalık } \\
(n=5211)\end{array}$ & $\begin{array}{c}\text { Tedavi } \\
(n=3820)\end{array}$ & $\begin{array}{l}\text { HT Kontrolü } \\
(n=3472)\end{array}$ \\
\hline \multicolumn{5}{|l|}{ Yaş } \\
\hline $30-39$ & 1 & 1 & 1 & 1 \\
\hline $40-49$ & $3,14(2,74-3,59)$ & $2,11(1,59-2,83)$ & $1,63(1,10-2,44)$ & $0,61(0,40-0,93)$ \\
\hline $50-59$ & $6,28(5,44-7,26)$ & $2,61(1,96-3,48)$ & $2,85(1,88-4,32)$ & $0,44(0,29-0,66)$ \\
\hline $60-69$ & $11,57(9,71-13,77)$ & $2,79(2,05-3,79)$ & $4,04(2,54-6,43)$ & $0,33(0,22-0,50)$ \\
\hline 70 ve üstü & $21,38(16,44-27,80)$ & $3,04(2,09-4,41)$ & $7,95(4,21-15,02)$ & $0,22(0,14-0,34)$ \\
\hline \multicolumn{5}{|l|}{ Cinsiyet } \\
\hline Kadın & 1 & 1 & 1 & 1 \\
\hline Erkek & $0,83(0,74-0,93)$ & $0,36(0,30-0,45)$ & $0,73(0,54-0,98)$ & $0,72(0,59-0,88)$ \\
\hline \multicolumn{5}{|l|}{ Medeni durum } \\
\hline Boşanmış & 1 & 1 & 1 & 1 \\
\hline Bekar & $1,06(0,72-1,54)$ & $1,64(0,83-3,24)$ & $1,38(0,47-4,14)$ & $0,48(0,23-0,99)$ \\
\hline Evli & $1,07(0,78-1,47)$ & $1,67(0,97-2,90)$ & $0,97(0,41-2,28)$ & $0,78(0,50-1,23)$ \\
\hline Dul & $1,28(0,90-1,80)$ & $1,88(1,05-3,37)$ & $1,16(0,47-2,89)$ & $0,61(0,33-1,13)$ \\
\hline \multicolumn{5}{|l|}{ Eğitim düzeyi } \\
\hline İlkokul ve altı & 1 & 1 & 1 & 1 \\
\hline Ortaokul ve lise & $0,92(0,78-1,09)$ & $0,93(0,72-1,19)$ & $1,38(0,97-1,95)$ & $1,01(0,83-1,24)$ \\
\hline Üniversite ve üstü & $0,73(0,60-0,87)$ & $1,10(0,82-1,49)$ & $1,39(0,91-2,11)$ & $0,99(0,76-1,28)$ \\
\hline \multicolumn{5}{|l|}{ Sosyal güvence } \\
\hline Yok & 1 & 1 & 1 & 1 \\
\hline Var & $1,11(0,91-1,36)$ & $1,05(0,73-1,52)$ & $2,07(1,26-3,23)$ & $1,29(0,86-1,93)$ \\
\hline \multicolumn{5}{|l|}{ Sağlık algısı } \\
\hline l̇yi & 1 & 1 & 1 & 1 \\
\hline Kötü & $1,22(1,11-1,34)$ & $1,65(1,40-1,94)$ & $0,85(0,66-1,09)$ & $1,02(0,88-1,19)$ \\
\hline \multicolumn{5}{|c|}{ Tadına bakmadan tuz kullanma } \\
\hline Hayır & 1 & 1 & 1 & 1 \\
\hline Evet & $0,78(0,69-0,89)$ & $0,52(0,42-0,65)$ & $0,70(0,50-0,99)$ & $0,97(0,77-1,23)$ \\
\hline \multicolumn{5}{|l|}{ Fizik aktivite } \\
\hline Yeterli & 1 & 1 & 1 & 1 \\
\hline Yetersiz & $1,21(1,10-1,33)$ & $0,99(0,84-1,16)$ & $1,00(0,79-1,27)$ & $1,04(0,90-1,21)$ \\
\hline \multicolumn{5}{|l|}{ Sigara } \\
\hline Hiç kullanmamış & 1 & 1 & 1 & 1 \\
\hline Kullanmış & $0,76(0,69-0,84)$ & $1,35(1,14-1,61)$ & $0,95(0,74-1,27)$ & $1,38(1,18-1,61)$ \\
\hline \multicolumn{5}{|l|}{ KKH varlığı } \\
\hline Hayır & 1 & 1 & 1 & 1 \\
\hline Evet & $1,72(1,43-2,08)$ & $4,35(3,15-6,03)$ & $1,82(1,20-2,76)$ & $1,13(0,94-1,37)$ \\
\hline \multicolumn{5}{|l|}{ İnme Varlığı } \\
\hline Hayır & 1 & 1 & 1 & 1 \\
\hline Evet & $2,78(1,89-4,07)$ & $2,03(1,20-3,42)$ & $0,63(0,36-1,06)$ & $0,72(0,51-1,02)$ \\
\hline \multicolumn{5}{|l|}{ Bel çevresi } \\
\hline Normal & 1 & 1 & 1 & 1 \\
\hline Yüksek & $2,58(2,34-2,85)$ & $1,17(1,01-1,39)$ & $1,63(1,28-2,11)$ & $0,56(0,48-0,66)$ \\
\hline \multicolumn{5}{|l|}{ Diyabet } \\
\hline Yok & 1 & 1 & 1 & 1 \\
\hline Var & $2,23(1,93-2,57)$ & $1,95(1,57-2,41)$ & $1,63(1,19-2,23)$ & $0,86(0,73-1,00)$ \\
\hline \multicolumn{5}{|l|}{ Hiperlipidemi } \\
\hline Yok & 1 & 1 & 1 & 1 \\
\hline Var & $1,30(1,18-1,43)$ & $1,46(1,25-1,72)$ & $1,29(1,02-1,63)$ & $1,07(0,87-1,23)$ \\
\hline \multicolumn{5}{|l|}{ Ailede KKH hikayesi } \\
\hline Yok & 1 & 1 & 1 & 1 \\
\hline Var & $3,84(3,49-4,24)$ & $12,72(10,72-15,08)$ & $1,30(0,88-1,93)$ & $1,41(1,12-1,78)$ \\
\hline
\end{tabular}

*HT: Hipertansiyon KKH: Koroner kalp hastalığı 
Çok değişkenli lojistik regresyon analizine göre tedavi alan bireylerde kan basıncının kontrol altında olma durumu artan yaş ile anlamlı olarak azalmıştır. Referans grup olan 30-39 yaş grubuna göre 70 yaş ve üstünde kan basıncı kontrolü için OR: $0,22(0,14-0,34)$ olarak bulunmuştur. Erkeklerde kan basıncı kontrolü kadınlara göre daha düşüktür; OR:0,72(\%95 GA:0,59-0,88). HT kontrolü, ailesinde KKH hikayesi olanlarda olmayanlara göre 1,41(\%95 GA:1,12-1,78) kat yüksektir. Medeni durumu bekar olan bireylerde kan basıncı kontrolü referans grup olan boşanmış bireylere göre anlamlı olarak düşüktür, OR: 0,48 (0,23-0,99). Artan eğitim düzeyi ve sosyal güvence varlığı ile kan basıncı kontrolü arasında anlamlı ilişki bulunmamıştır.

\section{TARTIŞMA}

Kentsel alanda yapılan bu çalışmada Balçova'da yaşayan 30 yaş üstü bireylerde HT sıklığı, farkında$1 \mathrm{k}$, tedavi ve kontrol düzeyleri ve bunları etkileyen etmenler incelenmiştir. Bu çalışmada, önceki çalışmalarda olduğu gibi HT prevalansının yaşla birlikte artış gösterdiği bulunmuştur. Yaş gruplarına göre değerlendirildiğinde 40-49 yaş grubunda her 3 kişiden birinde, 50-59 yaş grubunda ise her iki bireyden birinde HT vardır. Türkiye Kronik Hastalıklar ve Risk Faktörleri (TKrHRF) çalışmasına göre 45-54 yaş grubunda her üç kişiden birisinin yüksek tansiyonu bulunduğu bildirilmiştir [8]. Ülkemizde yap1lan TURDEP-I, TURDEP-II ve PATENT çalışmalarında da benzer bulgular elde edilmiştir [7,17,18]. Hipertansiyon Prevalans Araştırması'nda geriatrik popülasyonda ( $\geq 65$ yaş) HT prevalansı \%75 (erkeklerde $\% 67$, kadınlarda \%82) olarak saptanmıştır. TURDEP-I, TURDEP-II ve PATENT çalışmalarında 65-74 yaş grubu için HT sıklıkları erkeklerde s1rasiyla $\% 64,0, \% 60,9, \% 60,0$, kadınlarda ise $\% 75,8$, $\% 76,2, \% 69,4$ olarak bildirilmiştir. TKrHRF çalışmasına göre 65 yaş ve üstü bireylerde HT prevalans1 ise $\% 68$ (erkeklerde $\% 59$, kadınlarda \%76) olarak bildirilmiştir. Bu çalışmada ise HT prevalansı 60-69 yaş grubunda $\% 75,1,70$ yaş ve üstünde $\% 84,6$ 'dır.

Ülkemizde 2009 yılında 18 yaş üstü 10748 kişide yapılan CREDIT çalışmasında HT sıklığı $\% 32,7$, farkındalık düzeyi \%48,6 olarak bildirilmiştir[7]. Aynı çalışmada HT olan bireylerin \%31,5'i tedavi almakta ve \%16,4'ünün kan basinc1 kontrol altında bulunmaktadır. Patent çalışmasında HT sıklığ $\% 31,8$, farkındalık oranı $\% 40,7$ olup hipertansif bireylerin \%31,1'i tedavi almakta ve sadece \%8,1'inin kan basıncı kontrol altındadır. Aynı çalışmada hipertansiyonun farkında olma oranının kadınlarda erkeklere göre daha yüksek olduğu (\%48'e karşın \%28) bildirilmiştir [19]. 2012 yılında tekrarlanan PATENT 2 çalışması verilerine göre farkındalı oranı $\% 54,7$ 'ye, kontrol oranları ise $\% 28,7$ 'ye yükselmiştir [9]. TKrHRF çalışmasında göre HT farkındalık oranı $\% 48$ olarak saptanmış olup benzer biçimde kadınlarda farkındalık oranı erkeklerden daha yüksektir (\%58; \%36). TURDEP-II araştırmas1 sonuçlarına göre HT' de farkındalık oranı $\% 58$ 'dir ve yine farkındalık oranı kadınlarda erkeklerden daha fazladır (\%63; \%48) [18]. Erzincan'da 2009 yılında yapılan bir çalışmaya göre HT farkındalık düzeyi \%77,4 ve kan basıncı kontrol oranı \%33,9 olarak bildirilmiştir. Aynı çalışmada tüm hipertansifler içinde kan basıncı kontrol oranı ise $\% 26,2$ olarak bulunmuştur [20].

$\mathrm{Bu}$ çalışmada bireylerin \%73,3'ü hipertansiyonun olduğunun farkında, HT olan bireylerin $\% 66,7$ 'si kan basıncı düşürücü tedavi almakta ve \%33,0'ünün kan basıncı kontrol altında bulunmaktadır. Bu çalışmada da kadınların HT için farkındalık düzeyi erkeklere göre anlamı olarak yüksek bulunmuştur. Bu bağlamda kentsel ve sağlık hizmetine görece kolay ulaşan Balçova populasyonunda farkındalık, tedavi ve kontrol oranları diğer çalışmalara göre daha yüksektir.

Çok değişkenli lojistik regresyon analizi sonuçlarına göre HT varlığını artan yaş, kötü sağl1k algısı, yetersiz fiziksel aktivite, yüksek bel çevresi, KKH, inme, DM, hiperlipidemi ve ailede KKH öyküsünün olması anlamlı olarak artırmıştır. HT sıklığı kadınlarda, erkeklere göre anlamlı olarak daha s1k görülmektedir ve bu bulgu ülkemizde yapılan diğer çalışma sonuçlarıyla uyumludur. Üniversite ve üstü eğitim düzeyi olan bireylerin HT riski ilkokul ve altı eğitimi olan bireylere göre anlamlı olarak daha düşük bulunmuştur. Suudi Arabistan ve Vietnam'da yapılan çalışmalarda da düşük eğitim düzeyi, yetersiz fizik aktivite, obezite, diyabet ve hiperkolesterolemi varlığ $\mathrm{HT}$ 'nin önemli belirleyicileri olarak bulunmuştur [21-23]. Ürdün Ulusal Çalışması'na (2009) göre HT, artan yaş, sigara kullanımı ve diyabet varlığı ile pozitif ilişkili bulunmuştur [24]. Sigara kullanımı HT için temel risk etmenlerinden biri 
olmasına rağmen çalışmamızda hayatının herhangi bir döneminde düzenli sigara kullanmış bireylerde HT varlığ 1 daha düşük bulunmuştur. Benzer bulgu ülkemizde yapılan diğer çalışmalarda da bildirilmiştir $[20,25]$. Bunun nedeni çalışmamızın kesitsel olmasına bağlı olarak neden-sonuç ilişkisindeki ardışıklığın gözlenememesi ile ilişkili olabilir.

Çalışmamızda obez bireylerin, obezite açısından riski olmayan bireylere göre HT farkındalıklarının daha yüksek olduğu bulunmuştur. Bu bulgu yakın zamanda hem gelişmiş hem de gelişmekte olan ülkelerde yakın zamanda yürütülmüş araştırma sonuçları ile uyumludur $[7,26]$. Bunun nedeni obezite, sigara kullanımı ve DM, KKH gibi hastalıklar nedeniyle bireylerin sağlı hizmeti almış olmaları ve bu nedenle bu hastalığa erken tanı konması ve bilgilendirme yapılmış olması olmuş olabilir.

Kadın cinsiyet, kronik hastalık ve ailede $\mathrm{KKH}$ hikayesi varlığı farkındalık ve kontrolü artırırken erkek cinsiyet ve obezite varlığ 1 kontrol düzeylerini olumsuz etkilemektedir. Obezitesi olan bireylerde kan basıncı kontrol oranlarındaki düşüklüğün eşlik eden hastalıkların yanında obezitenin böbrek fonksiyonları ve morfolojisine olan karmaşı patofizyolojik etkilerinin neden olduğu yapılan çalışmalarda bildirilmiştir [27]. Farkındalığın yüksek olmasına rağmen kontrol oranlarının düşük olmasının nedenlerinin yeni çalışmalarla incelenmesi gerekmektedir.

Çalışmamızda yemeğin tadına bakmadan tuz kullanan bireylerde farkındalık ve tedavi olma anlamlı olarak düşüktür. Tuz tüketiminin oldukça yüksek olduğu toplumumuzda (18,01 gr/gün) tuz kisitlamasına yönelik farkındalığı artırıcı kampanyalar yürütülmeli ve toplumsal tuz tüketiminin azaltılmas1 için besin endüstrisinin besinlerin tuz içeriğini düşürücü maliyet-etkili girişimler ilgili bakanlıklarca uygulanmasının sağlanması kan basıncı kontrolü açısından yararlı olacaktır $[28,29]$. Tarım, Gıda ve Köy İşleri Bakanlığı 2013 yılında yaptığı düzenleme ile ekmeklerdeki tuz oranı azaltılmıştır.

Ülkemizde topluma dayalı HT kontrolüne yönelik girişim araştırmaları bildiğimiz kadarıyla yoktur. Bir çok ülkede topluma yönelik eğitim kampanyalarının, sağlıklı beslenme gibi olumlu yaşam biçim değişikliğine yönelik girişimler ve akılcı ilaç kullanımının HT yükünü azalttığı ve kan basınc1 kontrol oranlarını artırdı ğ bildirilmiştir [30,31].

Çalışmanın başlıca kısıtlılıkları, ulaşma oranının \%44 olması nedeniyle bulguların genellenebilirliğinin sınırlı olmasıdır. Ancak, son dönemde yapılan toplumsal çalışmalarda katılım oranlarının çalışmamızdakine benzer olarak tüm dünyada düşük olduğu gözlemlenmektedir ve küresel olarak bir düşüş söz konusudur. Örnek seçilmeden yapılan çalışmalara taranan hastalıklar açısından risk taşıyan bireylerin daha fazla katılabileceği görüşü hakim olsa da bulguların genellenebilirliğini inceleyen bir çalışma, risk taşıyan ve taşımayan bireylerin benzer oranlarda çalışmaya katılım gösterdiklerini bildirilmiştir(Taylor et al. 2006). Çalışmamızda erkeklerin katılım oranları kadınlara göre daha düşüktür. Bunun nedeni erkeklerin kan alımı ve tansiyon ölçümünün yapıldığı gündüz saatlerinde çalışmaları nedeniyle çalışmaya katılamamalarıdır. $\mathrm{Bu}$ sorun hafta sonu proje merkezinin belirli aralıklarla açılarak erkeklerin katılımının artırılması ile aşılmaya çalışılmıştır. Çalışmanın kesitsel olması nedeniyle nedensellik açısından bazı değişkenlerin etkilerinin yorumlanmasında dikkatli olunması gerekmektedir. Örnek olarak tadına bakmadan tuz kullanan bireylerde HT daha az görülmüştür, aslında beklenen ilişki tam tersi yönündedir, bireylerin daha önceden HT tanısı olduğu için bireylerin tuz kullanmaması daha olası gözükmektedir.

Sonuç olarak HT, \%41'lik bir prevalans ile Balçova'da önemli bir kronik sağlık sorunu ve bir risk faktörü olarak görünmektedir. HT yaşla birlikte artmaktadır ve kadınlarda daha yüksektir. Hastalığın farkında olma oranlarında ülkemizde önceki yıllara göre bir artış olmuştur ve Balçova'da HT için farkında olma oranları yüksektir. Ancak, hipertansiyonu olan bireylerin yaklaşık üçte birinin tansiyonu kontrol altında değildir. Kadınlarda HT'nin sık görülmesi, erkeklerde ise HT farkındalık, tedavi ve kontrolünün düşük olması önemli bir sorun olarak görülmektedir. Bu nedenle HT farkındalık düzeylerinin artırılmasını amaçlayan toplum taramalarının yanında, kan basıncı kontrolüne yönelik etkili tedavi uygulamaları ve sağlıklı yaşam biçim değişikliğine yönlendirici sağlığı geliştirici girişimler yaygınlaştırılmalıdır. 


\section{KAYNAKLAR}

1. Ezzati M, Lopez AD, Rodgers A, et al. Selected major risk factors and global and regional burden of disease. Lancet 2002, 360:1347-1360.

2. Mathers CD, Loncar D. Projections of global mortality and burden of disease from 2002 to 2030. PLoS Med 2006;3:e442.

3. Danaei G, Finucane MM, Lin JK

et al. National, regional, and global trends in systolic blood pressure since 1980: systematic analysis of health examination surveys and epidemiological studies with 786 country-years and 5.4 million participants. Lancet 2011;377:568-577.

4. Gaziano TA, Bitton A, Anand S, et al. The global cost of nonoptimal blood pressure. J Hypertens 2009;27:1472-1477.

5. Smith WC, Lee AJ, Crombie IK, et al. Control of blood pressure in Scotland: the rule of halves. BMJ 1990;300:981-983.

6. Chow CK, Teo KK, Rangarajan S, et al. Prevalence, awareness, treatment, and control of hypertension in rural and urban communities in high-, middle-, and low-income countries. JAMA 2013;310:959-968.

7. Altun B, Suleymanlar G, Utas C, et al. Prevalence, awareness, treatment and control of hypertension in adults with chronic kidney disease in Turkey: results from the CREDIT study. Kidney Blood Press Res 2012;36:36-46.

8. Ünal B, Ergör G: Türkiye Kronik Hastalıklar ve Risk Faktörleri Sıklığı Çalışması. In. Ankara: Sağlık Bakanlığı; 2013.

9. Sengul S, Erdem Y, Akpolat T, et al. Controlling hypertension in Turkey: not a hopeless dream. Kidney Int Suppl (2011) 2013;3:326-331.

10. Mancia G, De Backer G, Dominiczak A, et al. 2007 Guidelines for the Management of Arterial Hypertension: The Task Force for the Management of Arterial Hypertension of the European Society of Hypertension (ESH) and of the European Society of Cardiology (ESC). J Hypertens 2007;25:11051187.

11. Sozmen K, Baydur H, Simsek H, et al. Decomposing socioeconomic inequalities in self assessed health in Turkey. Int J Equity Health 2012;11:73.

12. Craig CL, Marshall AL, Sjostrom M, et al. International physical activity questionnaire: 12-country reliability and validity. Med Sci Sports Exerc 2003;35:1381-1395.

13. Grundy SM, Cleeman JI, Daniels SR, et al. Diagnosis and management of the metabolic syndrome: an American Heart Association/National Heart, Lung, and Blood Institute scientific statement: Executive Summary. Crit Pathw Cardiol 2005;4:198-203.

14. Graham I, Atar D, Borch-Johnsen K, et al. European guidelines on cardiovascular disease prevention in clinical practice: full text. Fourth Joint Task Force of the European Society of Cardiology and other societies on cardiovascular disease prevention in clinical practice (constituted by representatives of nine societies and by invited experts). Eur J Cardiovasc Prev Rehabil 2007;14 Suppl 2:S1-113.

15. National Cholesterol Education Program Expert Panel on Detection E, Treatment of High Blood Cholesterol in A. Third Report of the National Cholesterol Education Program (NCEP) Expert Panel on Detection, Evaluation, and Treatment of High Blood Cholesterol in Adults (Adult Treatment Panel III) final report. Circulation 2002, 106:3143-3421.
16. Ergor G, Soysal A, Sozmen K, et al. Balcova heart study: rationale and methodology of the Turkish cohort. Int J Public Health 2012;57:535-542.

17. Satman I, Yilmaz T, Sengul A, et al. Population-based study of diabetes and risk characteristics in Turkey: results of the Turkish Diabetes Epidemiology Study (TURDEP). Diabetes Care 2002;25:1551-1556.

18. Satman I, Omer B, Tutuncu Y, et al. Twelve-year trends in the prevalence and risk factors of diabetes and prediabetes in Turkish adults. Eur J Epidemiol 2013;28:169-180.

19. Altun B, Arici M, Nergizoglu G, et al. Prevalence, awareness, treatment and control of hypertension in Turkey (the PatenT study) in 2003. J Hypertens 2005;23:1817-1823.

20. Asilar RH, Inandi T, Yimdirim A, et al. Frequency, Awareness, Treatment and Control of Hypertension in the over $40 \mathrm{Popu}-$ lation of Erzincan. TAF Prev Med Bull 2014;13:357-366.

21. Ha DA, Goldberg RJ, Allison JJ, et al. Prevalence, Awareness, Treatment, and Control of High Blood Pressure: A Population-Based Survey in Thai Nguyen, Vietnam. PLoS One 2013;8:e66792.

22. Saeed AA, Al-Hamdan NA, Bahnassy AA, et al. Prevalence, Awareness, Treatment, and Control of Hypertension among Saudi Adult Population: A National Survey. Int J Hypertens 2011;2011:174135.

23. Gee ME, Campbell NR, Bancej CM, et al. Perception of uncontrolled blood pressure and behaviours to improve blood pressure: findings from the 2009 Survey on Living with Chronic Diseases in Canada. J Hum Hypertens 2012;26:188195.

24. Jaddou HY, Batieha AM, Khader YS, et al. Hypertension prevalence, awareness, treatment and control, and associated factors: results from a national survey, Jordan. Int J Hypertens 2011;2011:828797.

25. Dogan N, Toprak D, Demir S. Hypertension prevalence and risk factors among adult population in Afyonkarahisar region: a cross-sectional research. Anadolu Kardiyol Derg 2012; $12: 47-52$

26. Danon-Hersch N, Marques-Vidal P, Bovet P, et al. Prevalence, awareness, treatment and control of high blood pressure in a Swiss city general population: the CoLaus study. Eur J Cardiovasc Prev Rehabil 2009; 16:66-72.

27. Douketis JD, Sharma AM. The management of hypertension in the overweight and obese patient: is weight reduction sufficient? Drugs 2004;64:795-803.

28. Mason H, Shoaibi A, Ghandour R, et al. A cost effectiveness analysis of salt reduction policies to reduce coronary heart disease in four Eastern Mediterranean countries. PLoS One 2014;9:e84445.

29. Erdem Y, Arici M, Altun B, et al. The relationship between hypertension and salt intake in Turkish population: SALTURK study. Blood Press 2010;19:313-318.

30. Tunstall-Pedoe H, Connaghan J, Woodward M, et al. Pattern of declining blood pressure across replicate population surveys of the WHO MONICA project, mid-1980s to mid1990s, and the role of medication. BMJ 2006;332:629-635.

31. Nissinen A, Berrios X, Puska P. Community-based noncommunicable disease interventions: lessons from developed countries for developing ones. Bull World Health Organ 2001;79:963-970. 